Article

\title{
A Reduced Switch AC-AC Converter with the Application of D-STATCOM and Induction Motor Drive
}

\author{
Chaitanya Jibhakate ${ }^{1, *(\mathbb{D})}$, Madhuri Chaudhari ${ }^{1}$ and Mohan Renge ${ }^{2}$ \\ 1 Department of Electrical Engineering, Visvesvaraya National Institute of Technology, Nagpur 440010, India; \\ macavc@yahoo.com \\ 2 Department of Electrical Engineering, Shri Ramdeobaba College of Engineering and Management, \\ Nagpur 440013, India; mrenge@rediffmail.com \\ * Correspondence: chaitanya.jibhakate@students.vnit.ac.in; Tel.: +91-909-611-5118
}

Received: 10 May 2018; Accepted: 5 July 2018; Published: 10 July 2018

\begin{abstract}
In this paper, a reduced switch AC-DC-AC converter is used as a distribution static compensator (DSTATCOM) and induction motor drive. The AC-DC-AC nine switch converter (NSC) is a reduced switch topology of conventional 12 -switch back to back converter. With a $25 \%$ reduced switch count, NSC has lower losses when operated at constant frequency mode compared to twelve switch converter (TSC). The idea is to operate NSC input terminal as an active front-end rectifier to mimic synchronous generator (SG) operation. The induction motor is connected at the output of the NSC for irrigation application where no speed regulation is required. In distribution generation (DG), a large capacitor bank is used to deliver required reactive power. This may lead to over-voltage at the point of common coupling (PCC) when the load is turned off. To manage reactive power transfer at PCC, a control scheme is developed for NSC such that it can absorb or deliver reactive power with induction motor drive. Similar to SG, V-curve and inverted V-curve is plotted. The simulation and hardware results prove the feasibility of the proposed system.
\end{abstract}

Keywords: nine switch converter; synchronous generator; digital signal controller; static compensator, distribution generation

\section{Introduction}

DG system recently getting more popular concerning gradual depletion of conventional sources. Several government policies such as subsidized solar panels and incentives on interest rebate of the windmill encourage more generation of solar and wind energy. With the increase in the connection of these renewable energy sources to the grid give rise to power quality issues [1-3]. It is necessary to maintain the acceptable voltage range at PCC with the varying load conditions. To keep bus voltage healthy, it is necessary to control reactive power transfer at loading and low load condition. At loading condition, sufficient reactive power must be available to avoid voltage dip at PCC. In addition, under low load condition, reactive power must be controlled to circumvent unacceptable voltage rise. To regulate reactive power transfer a FACTS device D-STATCOM has been utilized [4-7].

In this paper, in view of controlling reactive power transfer, the D-STATCOM is integrated with induction motor drive using nine switch AC-DC-AC converter. The NSC is recently introduced reduced switch topology of conventional twelve switch converter (TSC) [8-16]. Various AC-AC topologies are available in the literature. In matrix converter, to increase lifespan of converter the common DC-link is eliminated at the cost of an increase in the number of active switches. It requires 18 active switches for AC-AC conversion. Thus; switch associated losses and complexity increases [17]. The effort is taken to reduce the switch count of matrix converter known as sparse matrix converter. However, with reduced 
switch count in sparse matrix converter, power flow become unidirectional [18,19]. Retaining common DC-link capacitor, another reduced switch topology found in [20], known as the B8 converter. It is the combination of two B4 converter which is connected back to back. In the B4 converter, four active switches form two phase legs while for third phase two split capacitors midpoint is used. The drawback of this arrangement is balancing two split capacitor voltage with large DC-link voltage variation [21].

The conventional AC-DC-AC converter for induction motor drive is made up of diode bridge rectifier followed by six active switches inverter. The disadvantage of this topology is that the input grid current is non-sinusoidal and has poor power factor operation. To improve quality of input current, the diode bridge rectifier is further replaced by active six switches converter known as back to back converter. It requires twelve active switches for AC-DC-AC conversion. In the proposed AC-DC-AC induction motor drive, only nine active switches are required which gives sinusoidal input current with desired power factor. The NSC turns out to be a better alternative for AC-DC-AC with reduced switch count. Many applications of NSC are found in literature because of its two three-phase terminal connection. It is used in an uninterrupted power supply (UPS) [13]. It is used to interface solar panels, battery, and ultra-capacitor output to the grid for DG system [14]. A compact battery charging system for an electric vehicle with the six-phase motor drive is reported in $[11,12]$. Depending on the terminal connection of NSC, it can be operated as DC-AC-AC, AC-DC-DC, and AC-DC-AC. Of course, with the reduce switch count, there are some operating constraints of the NSC. Application criteria of the NSC reported in $[15,16]$ clearly mentioned that the NSC when operated as AC-DC-AC with different frequency operation is not recommended as it requires double DC-link voltage when compared to TSC operation. It also states that, when NSC is operated in common AC-DC-AC frequency mode then along with reduced switch count, losses in the NSC are lesser when compared to TSC.

Considering the advantages of the NSC operated in common AC-DC-AC frequency mode, in the proposed system the three-phase induction motor is connected at the output which will run at constant speed. For irrigation application, a centrifugal pump is connected to the induction motor. In this application, there is no requirement of controlling speed. As induction motor is operated at lagging power factor, a control scheme is developed such that the NSC with induction motor can be operated as lagging, unity, and leading power factor. Operating the NSC at leading power factor can deliver reactive power to PCC. The NSC, when operated as lagging power factor, can absorb reactive power from PCC of the grid. The idea is to operate the NSC to mimic synchronous generator at the input side and induction motor drive for irrigation application at the output side.

This paper is organized as follows, Section 2 gives system description and operation of NSC. The generation of the gate signal and operating constraint is explained in Section 3 . The control logic of the proposed system is given in Section 4. Simulation and experimental results are presented in Sections 5 and 6 respectively. Finally, the conclusion is drawn in Section 7.

\section{System Description and Operation of NSC}

Figure 1 shows the overall single-line diagram of the three-phase power system connection. The NSC is connected at PCC with interfacing source inductance $\left(L_{s}\right)$. Along with the NSC, a different rating of reactive loads are also connected at the PCC. The $V_{s}$ is the grid phase voltage at PCC. The $i_{s}, i_{l}$, and $i_{a}$ are the source, reactive load, and NSC currents respectively. The aim is to maintain the unity power factor at PCC such that no reactive power exchange at the PCC. To achieve this, the NSC is controlled so that, when the inductive load is connected, NSC will deliver reactive power and when the capacitive load is connected, NSC will absorb reactive power. Figure 2 shows phasor representation of the operation of the NSC. In Figure 2a, at PCC along with the NSC, an inductive load is connected. Thus NSC is operated at leading power factor $\left(i_{a}\right.$ leads $\left.V_{s}\right)$ such that $V_{s}$ is in phase with $i_{s}$. Similarly when the capacitive load is connected at the PCC, the NSC is operated at lagging power factor $\left(i_{a}\right.$ lags $\left.V_{s}\right)$ resulting in-phase operation of $V_{s}$ and $i_{s}$. As shown in Figure 1 , a different rating of reactive load is connected at PCC to test the operation of NSC as DSTATCOM. 


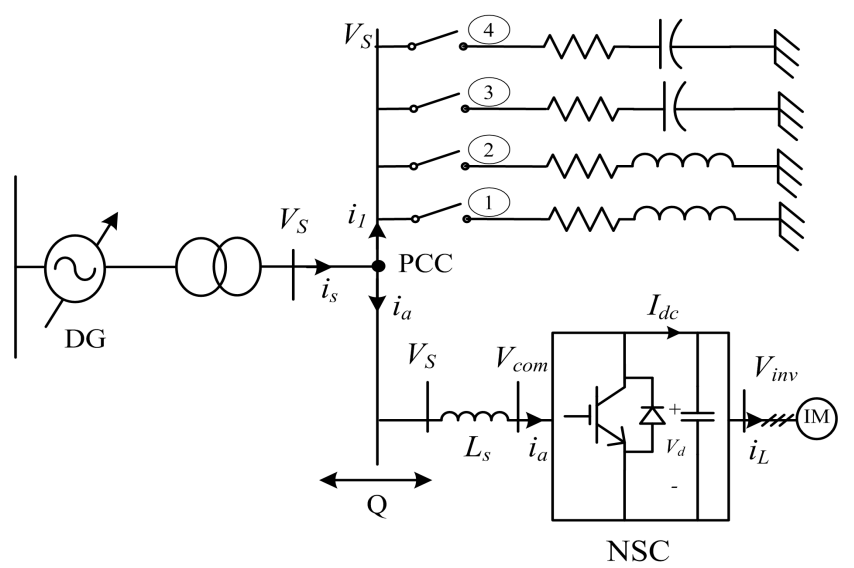

Figure 1. Single-line diagram of three-phase power system connection.

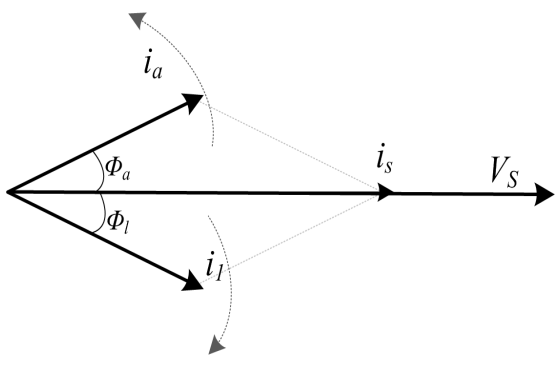

(a) NSC operated at leading power factor

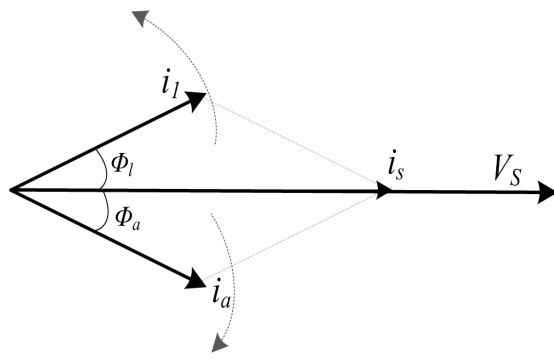

(b) NSC operated at lagging power factor

Figure 2. Phasor representation of operation of NSC. (a) NSC operated at leading power factor; (b) NSC operated at lagging power factor.

Figure 3 shows the arrangement of NSC operated as DSTATCOM and induction motor drive. The terminal $a, b$, and $c$ are the input points and the terminals $x, y$, and $z$ are the output points of the NSC. For simplicity it is assumed that upper six switches $\left(\mathrm{S}_{1}, \mathrm{~S}_{2}, \mathrm{~S}_{4}, \mathrm{~S}_{5}, \mathrm{~S}_{7}, \mathrm{~S}_{8}\right)$ act as a DSTATCOM and lower six switches $\left(\mathrm{S}_{2}, \mathrm{~S}_{3}, \mathrm{~S}_{5}, \mathrm{~S}_{6}, \mathrm{~S}_{8}, \mathrm{~S}_{9}\right)$ act as a inverter to drive induction motor which is coupled to the centrifugal pump. The $V_{c o m}$ and $V_{i n v}$ are the input and output terminal voltage of the NSC. The $V_{\text {com }}$ is the function of DC-link voltage $\left(V_{d}\right)$. The reactive power transfer depends on the difference between a magnitude of $V_{s}$ and $V_{\text {com }}$. The voltage $V_{s}$ is constant, thus by varying $V_{\text {com }}$, reactive power transfer can be altered. As $V_{c o m}$ is a function of $V_{d}$, to charge DC-link capacitor $\left(\mathrm{C}_{\mathrm{d}}\right)$ active power from PCC to NSC is transferred by varying power angle ' $\delta$ ' between $V_{s}$ and $V_{\text {com }}$. As the input terminal of the NSC is operated as active front end converter, to synchronize NSC at PCC, instantaneous angle ' $\theta$ ' of the PCC voltage is tracked. To measure this angle ' $\theta$ ', three-phase voltage is sensed by using voltage sensor. Synchronous reference frame phase lock loop (SRF-PLL) is implemented in the logic controller to extract angle ' $\theta$ ' [22]. In practical, to interface voltage sensor signal and logic controller, signal conditioning circuit is required. Along with sensing voltage, a current sensor is required to calculate the active and reactive power of the converter. Another voltage sensor is required to measure DC-link capacitor voltage. As $V_{i n v}$ is the output of the NSC, which is the function of DC-link voltage. To keep $V_{i n v}$ magnitude constant, the modulation index of an inverter is changed according to the variation in DC-link voltage. To get desired gate pulses of the NSC, logic is developed in a logic controller. The controller ePWM (enhance pulse width modulation) pulses of the controller are processed by buffer circuit, an isolation circuit, and gate driver circuit to operated active power switches. 


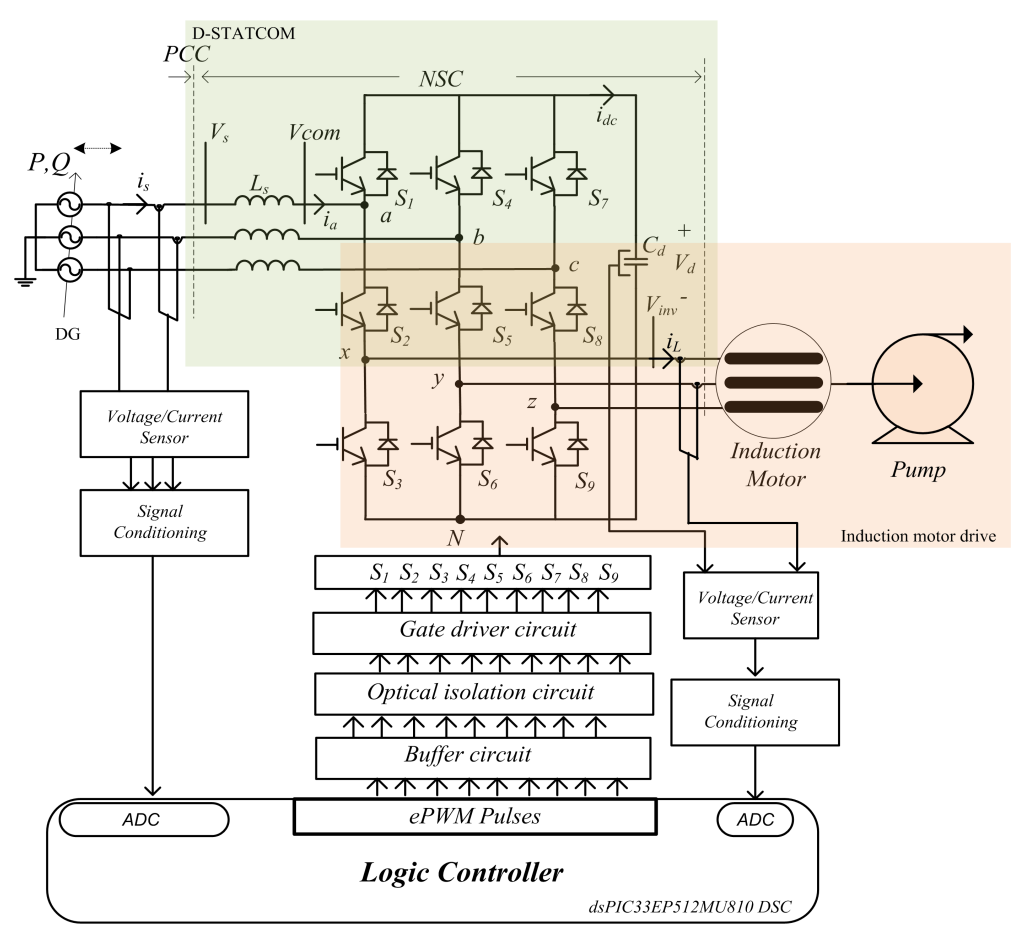

Figure 3. Arrangement of NSC operated as DSTATCOM and induction motor drive.

\section{Generation of Gate Signal and Operating Constraints of the NSC}

The AC-DC-AC NSC is operated as rectifier and inverter simultaneously. For rectifier and inverter operation two modulating references, $\operatorname{Ref}_{\text {rec }}$ and $\operatorname{Ref}_{\text {inv }}$ respectively is compared with a single carrier signal $\left(\mathrm{V}_{\mathrm{c}}\right)$. For front-end rectification operation, $\mathrm{Ref}_{\text {rec }}$ must be synchronized to the PCC. Thus; SRF-PLL is implemented to track instantaneous angle ' $\theta$ ' of the grid. Also, to control active power transfer between PCC and NSC, the reference Ref $_{\text {rec }}$ is shifted by an angle ' $\delta$ ' with respect to the PCC voltage. Figure 4 shows the PCC voltage and phase shifted references by an angle ' $\delta$ '. The Three-phase modulating references of the NSC are given by-

$$
\begin{aligned}
& R e f_{\text {rec_a }}=m_{\mathrm{r}} \sin (\theta+\delta)+V_{\mathrm{dc} \_ \text {offset }} \\
& R e f_{\text {rec_b }}=m_{\mathrm{r}} \sin \left(\theta-120^{\circ}+\delta\right)+V_{\mathrm{dc} \_ \text {offset }} \\
& \operatorname{Re} f_{\text {rec_c }}=m_{\mathrm{r}} \sin \left(\theta+120^{\circ}+\delta\right)+V_{\mathrm{dc} \_ \text {offset }} \\
& \operatorname{Re} f_{\text {inv_x }}=m_{\mathrm{i}} \sin (\theta+\delta)-V_{\mathrm{dc} \_ \text {offset }} \\
& R e f_{\text {inv_y }}=m_{\mathrm{i}} \sin \left(\theta-120^{\circ}+\delta\right)-V_{\mathrm{dc} \_ \text {offset }} \\
& \operatorname{Re} f_{\text {inv_z }}=m_{\mathrm{i}} \sin \left(\theta+120^{\circ}+\delta\right)-V_{\mathrm{dc} \_ \text {offset }}
\end{aligned}
$$

where $m_{r}$ and $m_{i}$ are the modulation indices of $\operatorname{Ref}_{\text {rec }}$ and $\operatorname{Ref}_{\text {inv }}$. The angle ' $\theta$ ' is an instantaneous angle of the PCC voltage tracked by SRF-PLL. The angle ' $\delta$ ' is a phase shift angle. To understand the generation of the gate signal of the NSC, one leg of the NSC is considered. There are eight possible switching states. Table 1 shows switching states and associated pole voltages. Among that eight switching states only three valid states are possible for the operation of the NSC. From Table 1, it is observed that pole voltage $\mathrm{V}_{\mathrm{aN}}$ is always greater than or equal to $\mathrm{V}_{\mathrm{xN}}$. Hence; modulating reference Ref $_{\text {rec }}$ is always kept above Ref $f_{\text {inv }}$. Thus; to achieve switching constraint a small DC-offset is added and subtracted from $\operatorname{Ref}_{\text {rec }}$ and Ref $_{\text {inv }}$. The switching constraint is applied to avoid short circuit of a DC-link capacitor or open circuit condition of the inductive load. Figure 5 shows the generation of gate pulses and pole voltage. When $\operatorname{Re}_{\text {rec }}$ is greater than the $V_{c}$, gate signal for $S_{1}$ is generated. 
When $\operatorname{Ref}_{\text {inv }}$ is lower than the $V_{c}$, gate signal for $S_{3}$ is generated. Applying XOR logic to the gate signal of $S_{1}$ and $S_{3}$, gate signal for $S_{2}$ is obtained.

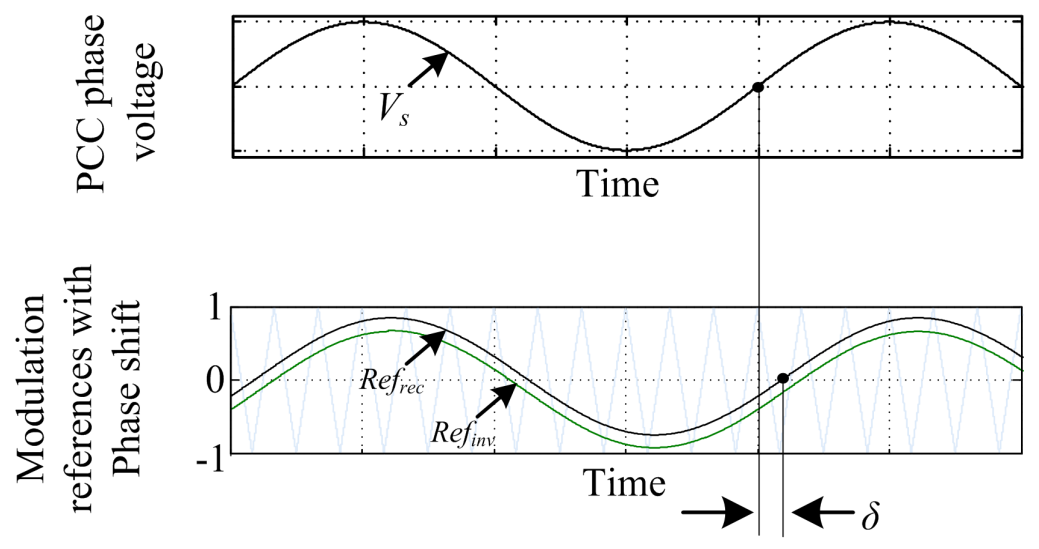

Figure 4. PCC voltage and phase shifted references by an angle ' $\delta$ '.

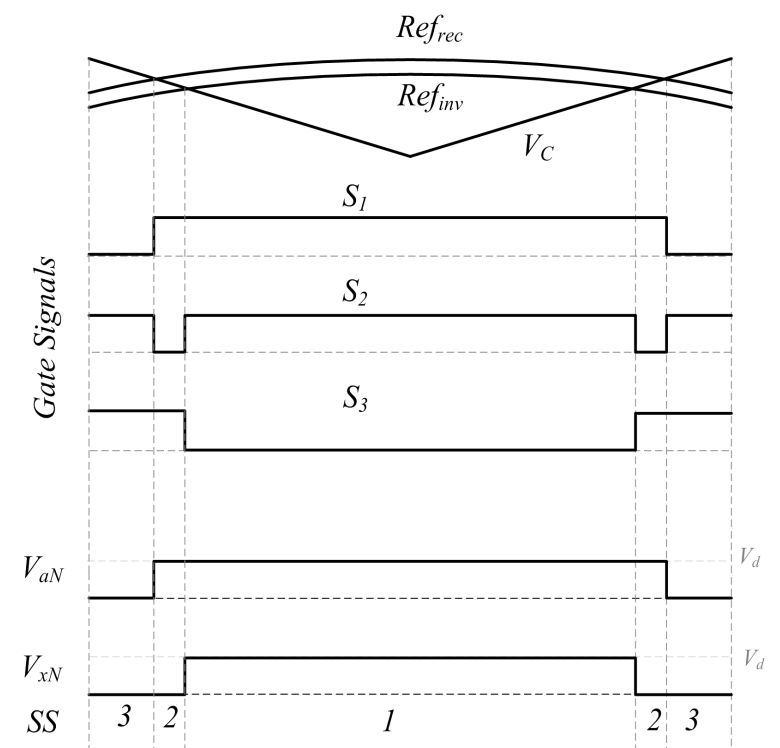

Figure 5. Generation of gate pulses.

Table 1. Switching states.

\begin{tabular}{cccccc}
\hline Switching States (SS) & $\mathbf{S}_{\mathbf{1}}$ & $\mathbf{S}_{\mathbf{2}}$ & $\mathbf{S}_{\mathbf{3}}$ & $\mathbf{V}_{\mathbf{a N}}$ & $\mathbf{V}_{\mathbf{x N}}$ \\
\hline \multicolumn{7}{c}{ Valid states } \\
\hline 1 & 1 & 1 & 0 & $V_{d}$ & $V_{d}$ \\
2 & 1 & 0 & 1 & $V_{d}$ & 0 \\
3 & 0 & 1 & 1 & 0 & 0 \\
\hline 4 & Forbidden states \\
5 & 1 & 1 & 1 & 0 & 0 \\
6 & 0 & 0 & 0 & 0 & 0 \\
7 & 1 & 0 & 0 & $V_{d}$ & 0 \\
8 & 0 & 1 & 0 & 0 & 0 \\
& 0 & 0 & 1 & 0 & 0 \\
\hline \multicolumn{7}{c}{}
\end{tabular}




\section{Control Logic of the Proposed System}

To control NSC, sinusoidal pulse width modulation technique is incorporated. A common DC-link is shared for both the rectifier and inverter operation. The rectifier input and inverter output voltage is a function of DC-link voltage and it is given by

$$
\begin{aligned}
& V_{\text {com }}=R e f_{r e c} V_{d} / 2 \\
& V_{i n v}=R e f_{i n v} V_{d} / 2
\end{aligned}
$$

In the proposed system, NSC is connected to PCC with the source inductance. Figure 6 shows the single line diagram of the connection of the NSC to PCC with $L_{s}$ which have its internal resistance $R_{s}$. The PCC voltage $V_{s} \angle 0$ is a reference voltage while $V_{\text {com }} \angle \delta$ is a variable voltage as it depends on the dc-link voltage of the NSC. The reactive power flow depends on the voltage magnitude of $\left|V_{s}\right|$ and $\left|V_{\text {com }}\right|$ and the active power flow depends on power angle between $V_{s}$ and $V_{\text {com }}$. From Figure 6, rectifier input voltage $V_{\text {com }}$ is given by

$$
V_{\text {com }}=V_{s}-\left(R_{s}+j X_{s}\right) i_{a}
$$

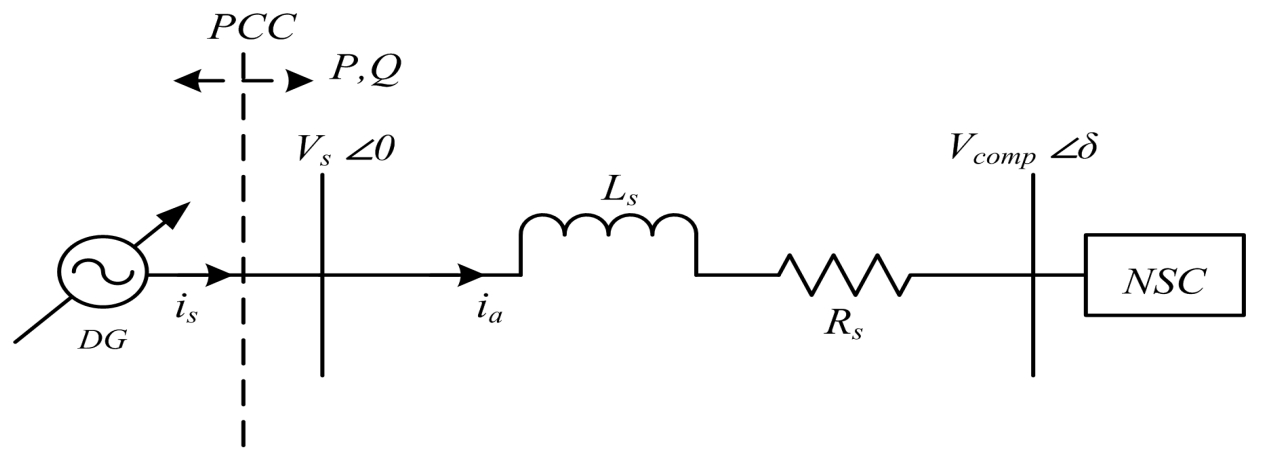

Figure 6. Single line diagram of the connection of the NSC to PCC.

Resolving $i_{a}$ in $d-q$ plane,

$$
i_{a}=i_{a d}^{*}+j i_{a q}^{*}
$$

where $i_{a d}$-active component, $i_{a q}$-reactive component. By controlling $i_{a d}$ and $i_{a q}$ current component of the NSC active and reactive power flow of the NSC is controlled. From (5) and (4)

$$
V_{c o m}=\left(V_{s}-R_{s} i_{a d}^{*}+X_{s} i_{a q}^{*}\right)-j\left(R_{s} i_{a q}^{*}+X_{s} i_{a d}^{*}\right)
$$

The magnitude and angle of $V_{\text {com }}$ is given by

$$
V_{\text {com }}=\left|V_{\text {com }}\right| \angle \delta
$$

where

$$
\begin{gathered}
\left|V_{c o m}\right|=\sqrt{\left(V_{s}-R_{s} i_{a d}^{*}+X_{s} i_{a q}^{*}\right)^{2}+\left(R_{s} i_{a q}^{*}+X_{s} i_{a d}^{*}\right)^{2}} \\
\angle \delta=\tan ^{-1} \frac{\left(R_{s} i_{a q}^{*}+X_{s} i_{a d}^{*}\right)}{\left(V_{s}-R_{s} i_{a d}^{*}+X_{s} i_{a q}^{*}\right)}
\end{gathered}
$$


To calculate $\mathrm{i}^{*}$ aq current reference, reactive power of the PCC is continuously monitored. In addition, to calculate $i_{\text {ad }}^{*}$ reference output power of the NSC is measured. The active and reactive power in $d-q$ reference is given by

$$
\begin{gathered}
P(t)=\frac{3}{2}\left[V_{d}(t) i_{d}(t)+V_{q}(t) i_{q}(t)\right] \\
Q(t)=\frac{3}{2}\left[-V_{d}(t) i_{q}(t)+V_{q}(t) i_{d}(t)\right]
\end{gathered}
$$

Aligning the $d$-axis of the input and out voltage of the NSC with the d-axis of the synchronous reference frame.

For input side of the NSC

$$
V_{d}=V_{\text {comd }}
$$

For output side of the NSC

$$
V_{d}=V_{\text {invd }}
$$

As the $q$-axis is orthogonal to the reference axis

$$
V_{q}=0
$$

By using Equations (10)-(14), active power of NSC input and output is given by

$$
P_{\text {in }}=\frac{3}{2}\left[V_{\text {comd }} i_{\text {ad }}\right]
$$

Bu using Equations (6), (10), and (11), real power at the inverter output side is given by:

$$
P_{\text {out }}=\frac{3}{2}\left[V_{\text {invd }} i_{L d}\right]
$$

where $i_{L d}$ is a $d$-axis component of the load current. Assuming NSC to be lossless converter and applying power balance criteria,

$$
\begin{aligned}
P_{\text {in }} & =P_{\text {out }} \\
\frac{3}{2}\left[V_{\text {com }} i_{\text {ad }}\right] & =\frac{3}{2}\left[V_{\text {invd }} i_{L d}\right]
\end{aligned}
$$

As the same dc-link is shared by the rectifier and inverter, $V_{\text {comd }}$ and $V_{\text {invd }}$ is given by:

$$
\begin{aligned}
& V_{\text {comd }}=\operatorname{Ref}_{\text {rec }} V_{d} / 2 \\
& V_{\text {invd }}=\operatorname{Ref}_{\text {inv }} V_{d} / 2
\end{aligned}
$$

The $\mathrm{m}_{\mathrm{r}}$ and $\mathrm{m}_{\mathrm{i}}$ are the only variable in $R e f_{r e c}$ and $R e f_{\text {inv }}$, Thus; by using Equations (18)-(20)

$$
i_{a d}=\left[\frac{m_{i}}{m_{r}}\right] i_{L d}
$$

Equation (21), gives relation between source current and load current in terms of modulation index of rectifier and inverter reference. The $i_{L d}$ is active component of the load current. Thus;

$$
i_{a d}=\left[\frac{m_{i}}{m_{r}}\right] i_{L} \cos \phi_{o}
$$

where $\phi_{0}$ is load phase angle. The $i_{L} \cos \phi_{0}$ is calculated from measured output power. Thus; $i_{\text {ad }}^{*}$ reference is generated. To calculate $i_{a q}^{*}$, reactive current component $\left(i_{s} \sin \phi\right)$ of the PCC current is measured. The aim is to maintain zero reactive power at PCC. Thus, the $i_{s} \sin \phi$ is compared with zero reference so as get desired $i_{a q}^{*}$. Figure 7 shows the proposed control diagram. The calculated $i_{a d}^{*}$ and $i_{a q}^{*}$ is fed to the phase shift generator block which generates desired phase shift to control active power or to charge 
DC-link capacitor at desired voltage level. The extracted PLL angle $\theta$ and angle $\delta$ is used to generate desired gate pulses for the operation of NSC.

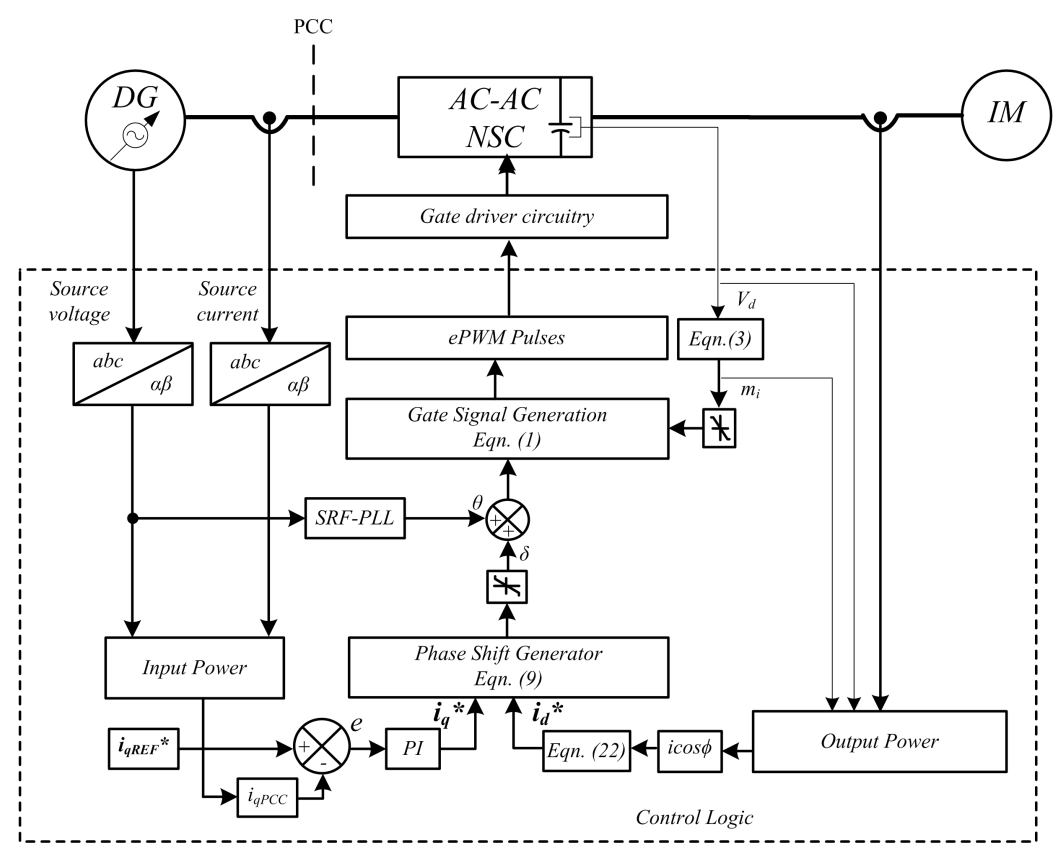

Figure 7. Control scheme.

\section{Simulation Result}

The MATLAB simulation is carried out considering different load conditions at PCC. The simulation parameters are given in Table 2. To maintain unity power factor operation at PCC, the reference current $i_{\text {qREF }}^{*}$ is kept as 0 . Referring to Figure 1, to test the dynamic performance of the proposed control technique different reactive loads are connected for different time duration. The time duration of different load connection is given in Table 2. The switching frequency $\left(\mathrm{F}_{\mathrm{sw}}\right)$ of the NSC is $9 \mathrm{kHz}$. The modulation index of a rectifier is kept constant at 0.8 , whereas modulation index of an inverter is varying to keep $V_{i n v}$ constant. To satisfy switching constraint a small dc-offset of $0.1 \mathrm{pu}$ is added only in rectifier references. The NSC input and output line voltages are shown in Figure 8.

Table 2. Simulation parameter.

\begin{tabular}{cc}
\hline$V_{s}$ & 3-Phase, $400 \mathrm{~V}, \mathbf{5 0 ~ H z}$ \\
\hline Induction Motor & $5.4 \mathrm{hp}, 4$ pole, $400 \mathrm{~V}, 50 \mathrm{~Hz}$ \\
\hline$L_{s}, R_{s}, m_{r}, \mathrm{~F}_{\mathrm{sw}}$ & $10 \mathrm{mH}, 1.63 \Omega, 0.8,9 \mathrm{kHz}$ \\
\hline \multicolumn{2}{c}{ Load at PCC } \\
\hline 1-R-L & $25 \Omega, 0.1 \mathrm{H}[0-1 \mathrm{~s}]$ \\
\hline 2-R-L & $25 \Omega, 0.3 \mathrm{H}[1-2 \mathrm{~s}]$ \\
\hline No-load & {$[2-3 \mathrm{~s}]$} \\
\hline 3-R-C & $25 \Omega, 30 \mu \mathrm{F}[3-4 \mathrm{~s}]$ \\
\hline 4-R-C & $25 \Omega, 60 \mu \mathrm{F}[4-5 \mathrm{~s}]$ \\
\hline
\end{tabular}



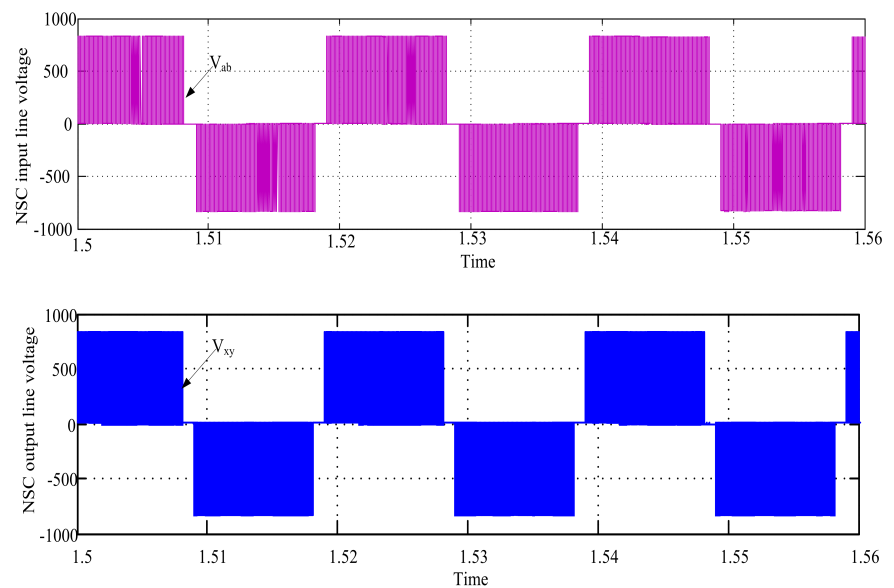

Figure 8. NSC input and output line voltages: $V_{a b}, V_{x y}(500 \mathrm{~V} / \mathrm{div}, 10 \mathrm{~ms} / \mathrm{div})$.

Figure 9 shows the exchange of the three-phase reactive power transfer under varying load conditions. During $0-1 \mathrm{~s}, 3100$ VAR reactive power $\left(\mathrm{Q}_{\text {load }}\right)$ is absorbed by the $\mathrm{R}-\mathrm{L}$ load. Thus; to maintain zero reactive power $\left(Q_{\text {ref }}\right)$ transfer at PCC, NSC delivers -3100 VAR $\left(Q_{N S C}\right)$ so that actual reactive power $\left(Q_{\text {act }}\right)$ is equals to $Q_{\text {ref. }}$ Similarly, during 1-2 s, 1550 VAR is absorbed by an R-L load, thus NSC provided - 1550 VAR to the PCC. During 2-3 s, no load is connected parallel to the NSC, thus there is no exchange of reactive power at PCC. During 3-4 s, an R-C load is connected which delivers -1400 VAR reactive power, thus NSC absorbs 1400 VAR from PCC. Similarly, for 4-5 s, R-C load delivers -2450 VAR, thus NSC absorbs 2450 VAR from PCC to maintain zero reactive power at PCC.

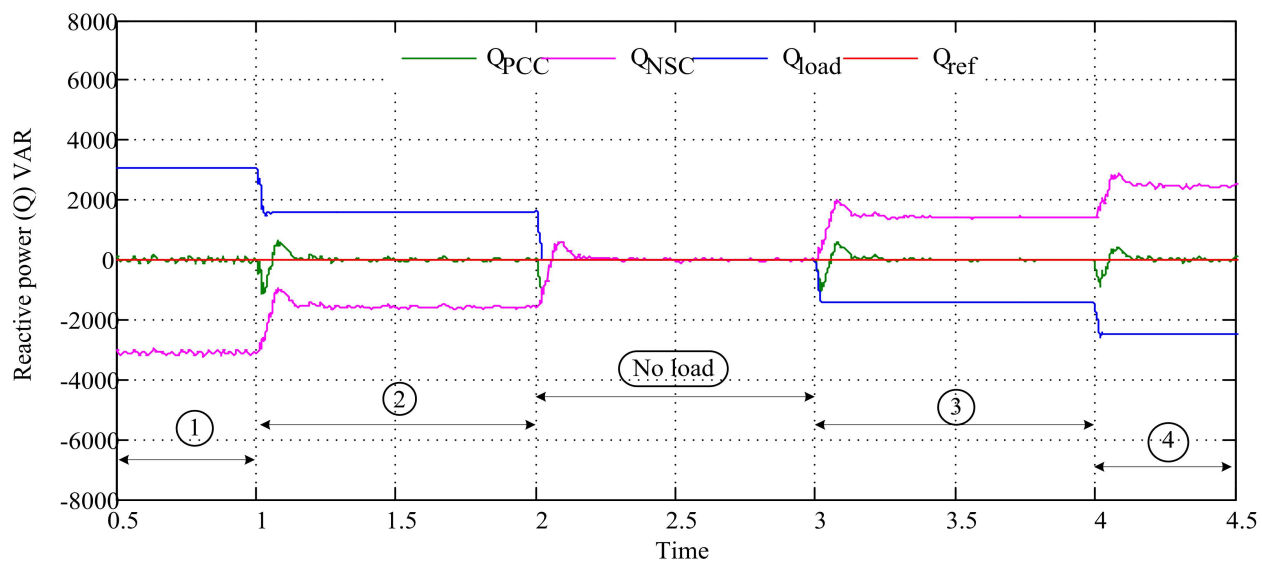

Figure 9. Exchange of three-phase reactive power at PCC: Q (2000 VAR/div, $0.5 \mathrm{~s} / \mathrm{div})$.

Figures 10 and 11 show the effect of varying load conditions on the NSC phase current $\left(i_{a}\right)$ and power factor of the NSC respectively. Figure 10a shows, during $0-1 \mathrm{~s}$ the NSC is operated at 0.8 leading power factor $\left(i_{a}\right.$ leads $V_{s}$ ). After the change in load, NSC changed its operation to 0.93 leading power factor. When there is no load connected parallel to the NSC at $2 \mathrm{~s}$, the NSC switched its operation from 0.93 lead to 0.999 unity power factor ( $i_{a}$ in-phase to $V_{s}$ ) as shown in Figure 10b. Figure 10c shows at $3 \mathrm{~s}$ when an R-C load is connected at PCC, the NSC is operated at 0.95 lagging power factor $\left(i_{a}\right.$ lags $\left.V_{s}\right)$. At $4 \mathrm{~s}$ when an R-C load is changed, the NSC shifted its operation from 0.95 lagging power factor to 0.86 lagging power factor as shown in Figure 10d. 


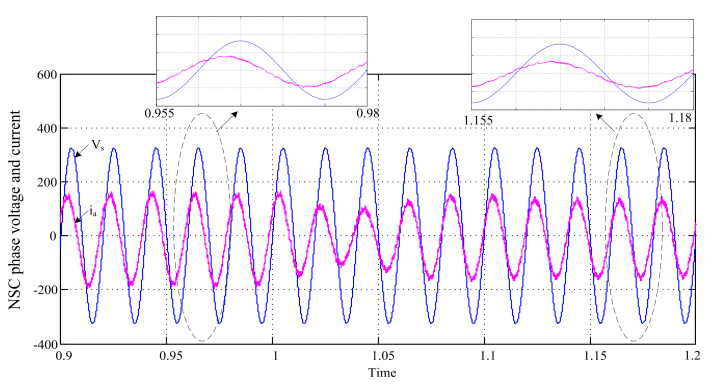

(a)

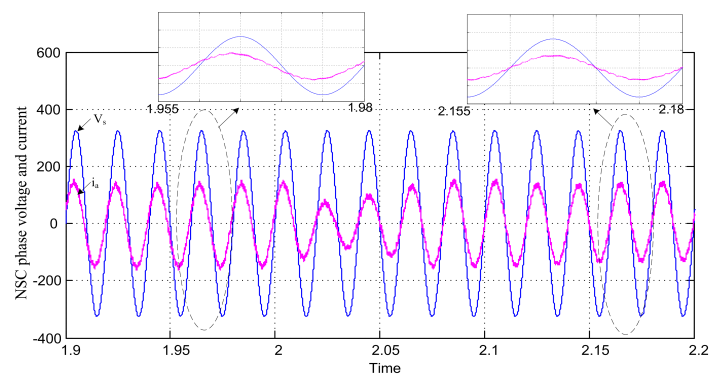

(b)

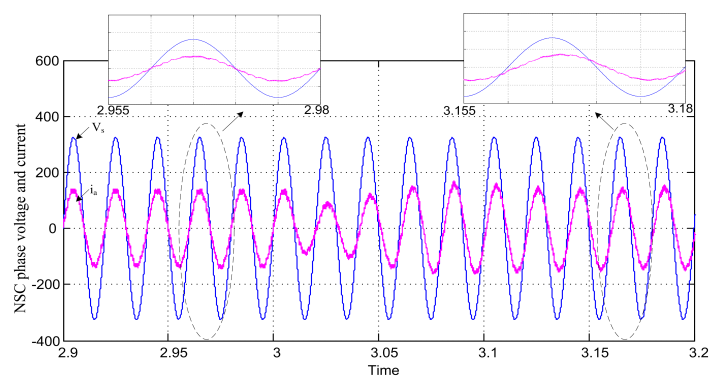

(c)

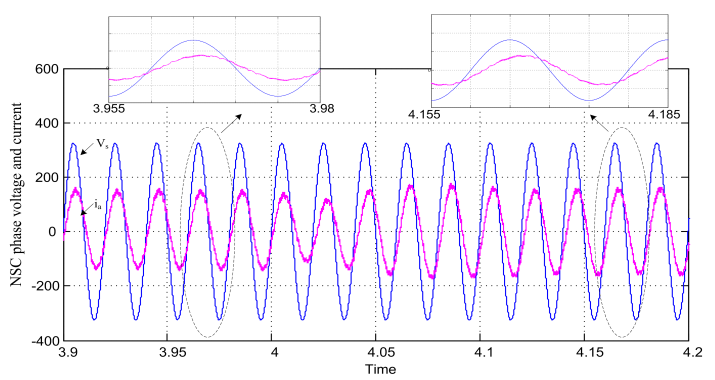

(d)

Figure 10. Phase voltage and NSC phase current under various load conditions: $V_{s}, 15 * i_{a}(200 \mathrm{~V} / \mathrm{div}$, $200 \mathrm{~A} /$ div, $50 \mathrm{~ms} / \mathrm{div})$.

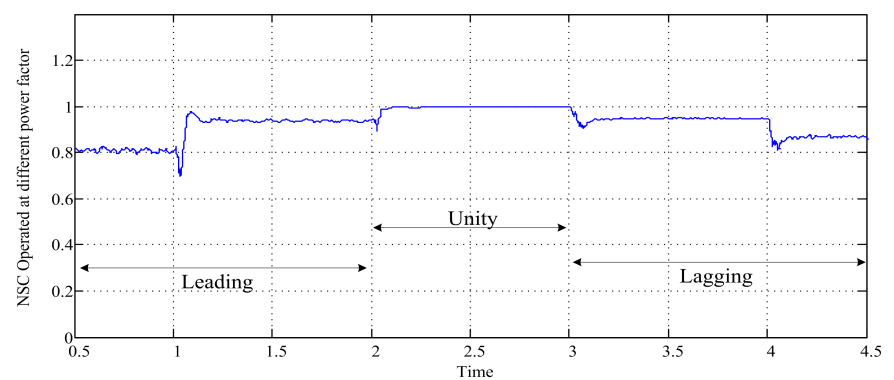

Figure 11. NSC operated at different power factor: $(0.2 \mathrm{pu} / \mathrm{div}, 0.5 \mathrm{~s} / \mathrm{div})$.

Figures 12 and 13 show a change in DC-link capacitor voltage and the angle $\delta$ respectively. As earlier discussed, the reactive power transfer from NSC to PCC depends on voltage magnitude of $V_{s}$ and $V_{\text {com }}$. As $V_{\text {com }}$ depends on DC-link voltage, with the changed in DC-link voltage $V_{\text {com }}$ varies and thus reactive power transfer varies. In a simulation, at first, NSC delivered reactive power thus at that instant required DC-link is more. With the change in load, NSC changed its operation from delivering to absorbing reacting power. Thus, according to a required magnitude of $V_{\text {com }}$, DC-link voltage is varied as shown in Figure 12. To charge or discharge the DC-link capacitor the angle $\delta$ is varied as 
per desired DC-link voltage requirement and finally, it settled down. As a common DC-link is shared for rectifier and inverter function of the NSC, with the change in DC-link voltage $V_{\text {inv }}$ also changes. To maintain $V_{\text {inv }}$ constant, $m_{i}$ is varied to keep NSC output voltage constant. Figure 14 show change in modulation index of the inverter. Figures 15 and 16 show induction motor three-phase current and speed under dynamic load variations at PCC.

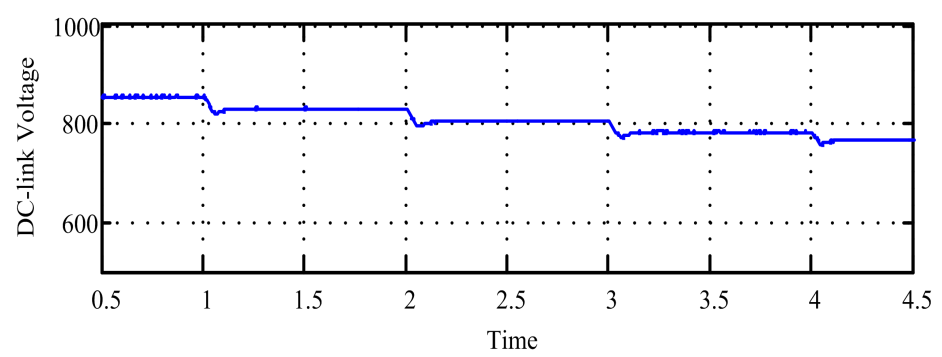

Figure 12. DC-Link capacitor voltage: ( $200 \mathrm{~V} / \mathrm{div}, 0.5 \mathrm{~s} / \mathrm{div})$.

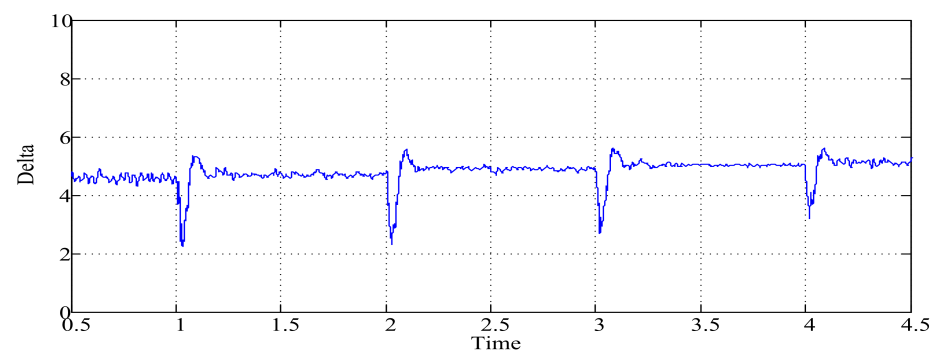

Figure 13. Change in angle delta $(\delta):(2 \mathrm{deg} / \mathrm{div}, 0.5 \mathrm{~s} / \mathrm{div})$.

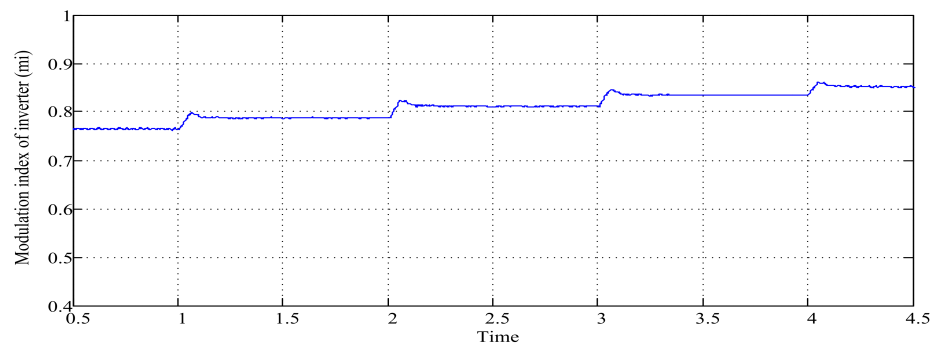

Figure 14. Change in modulation index of inverter: $m_{i}(0.1 \mathrm{pu} / \mathrm{div}, 0.5 \mathrm{~s} / \mathrm{div})$.

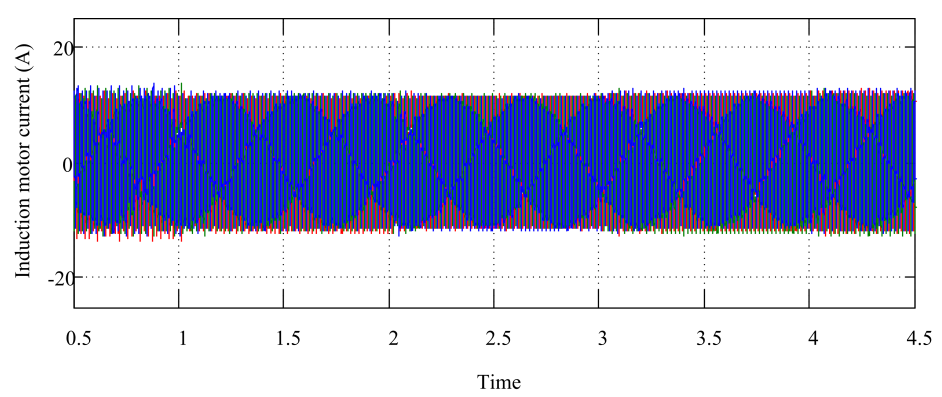

Figure 15. Three-phase induction motor current: $i_{L}(10 \mathrm{~A} / \mathrm{div}, 0.5 \mathrm{~s} / \mathrm{div})$. 


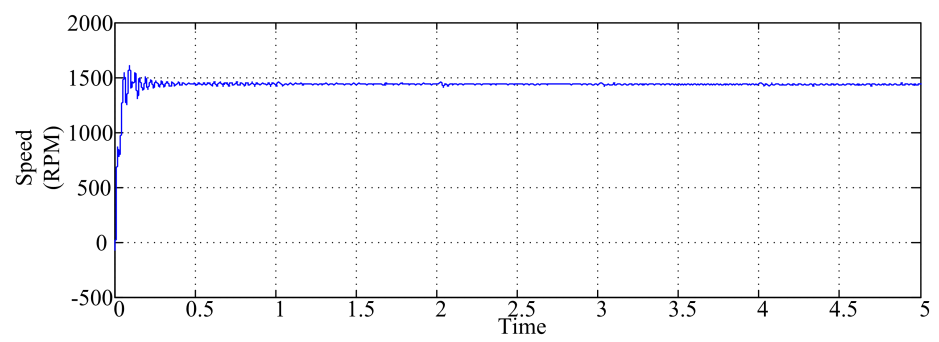

Figure 16. Induction motor speed: (500 RPM/div, $0.5 \mathrm{~s} / \mathrm{div})$.

The simulation results are summarized in Table 3. It is observed that the input rectifier operation of the NSC mimics the operating principle of the synchronous generator. The synchronous generator delivers reactive power when its field is over-excited and absorbs reactive power when its field is under-excited. The V-curve and inverted V-curve is obtained by varying field excitation of the synchronous motor. A Similar phenomenon is observed in case of the NSC. By controlling DC-link voltage of the NSC reactive power transfer can be controlled. From simulation results shown in Table 3, V-curve and inverted V-curve is plotted in Figure 17.

Table 3. Simulation results.

\begin{tabular}{|c|c|c|c|c|c|c|c|}
\hline \multicolumn{8}{|c|}{$\left[V_{s}=230 \mathrm{~V} /\right.$ phase, $\left.m_{r}=0.8\right]$} \\
\hline & $\begin{array}{c}i_{a}(\mathrm{~A}) \\
\% \text { THD }\end{array}$ & $\cos \phi_{\mathrm{a}}$ & $\begin{array}{l}V_{a b 1}(\mathrm{~V}) \\
\% \text { THD }\end{array}$ & $V_{d}(\mathrm{~V})$ & $\mathrm{Q}_{\mathrm{NSC}}(\mathrm{VAR})$ & $\begin{array}{l}V_{x y 1}(\mathrm{~V}) \\
\% \text { THD }\end{array}$ & $\begin{array}{c}i_{L} \text { (A) } \\
\% \text { THD }\end{array}$ \\
\hline (1) $0-1 \mathrm{~s}$ & $\begin{array}{c}7.8 \\
4.5 \%\end{array}$ & $\begin{array}{c}0.8 \\
\text { lead }\end{array}$ & $\begin{array}{c}424.2 \\
32.10 \%\end{array}$ & 854 & -3100 & $\begin{array}{c}400 \\
32.24 \%\end{array}$ & $\begin{array}{l}7.8 \\
4.9\end{array}$ \\
\hline (2) $1-2 \mathrm{~s}$ & $\begin{array}{c}6.72 \\
4.9 \%\end{array}$ & $\begin{array}{l}0.93 \\
\text { lead }\end{array}$ & $\begin{array}{c}412.3 \\
32.16 \%\end{array}$ & 830 & -1550 & $\begin{array}{c}400 \\
32.24 \%\end{array}$ & $\begin{array}{l}7.8 \\
4.8\end{array}$ \\
\hline No-load 2-3 s & $\begin{array}{c}6.318 \\
4.93 \%\end{array}$ & $\begin{array}{l}0.999 \\
\text { unity }\end{array}$ & $\begin{array}{c}400 \\
32.16 \%\end{array}$ & 805 & 0 & $\begin{array}{c}400 \\
31.91 \%\end{array}$ & $\begin{array}{l}7.8 \\
3.8\end{array}$ \\
\hline (3) $3-4 \mathrm{~s}$ & $\begin{array}{c}6.67 \\
4.58 \% \\
\end{array}$ & $\begin{array}{c}0.95 \\
\text { lag }\end{array}$ & $\begin{array}{c}388.9 \\
32.01 \%\end{array}$ & 783 & 1420 & $\begin{array}{c}400 \\
31.7 \% \\
\end{array}$ & $\begin{array}{l}7.8 \\
4.0 \\
\end{array}$ \\
\hline (4) $4-5 \mathrm{~s}$ & $\begin{array}{c}7.32 \\
4.36 \%\end{array}$ & $\begin{array}{l}0.86 \\
\text { lag }\end{array}$ & $\begin{array}{c}380.7 \\
31.97 \%\end{array}$ & 767 & 2450 & $\begin{array}{c}400 \\
31.56 \%\end{array}$ & $\begin{array}{c}7.8 \\
4.89\end{array}$ \\
\hline
\end{tabular}

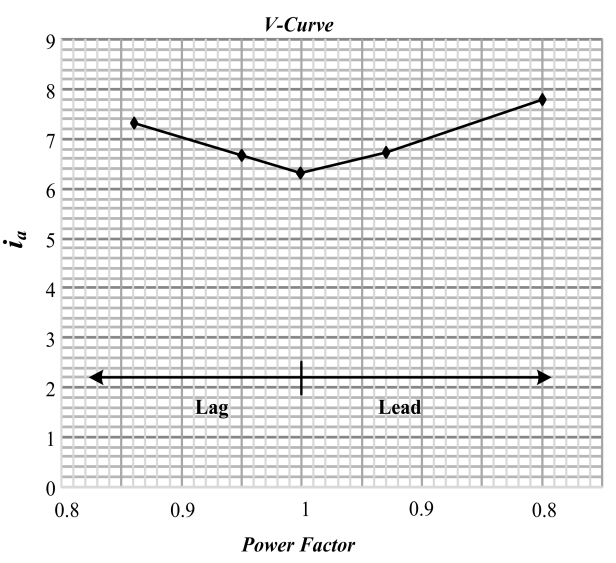

(a)

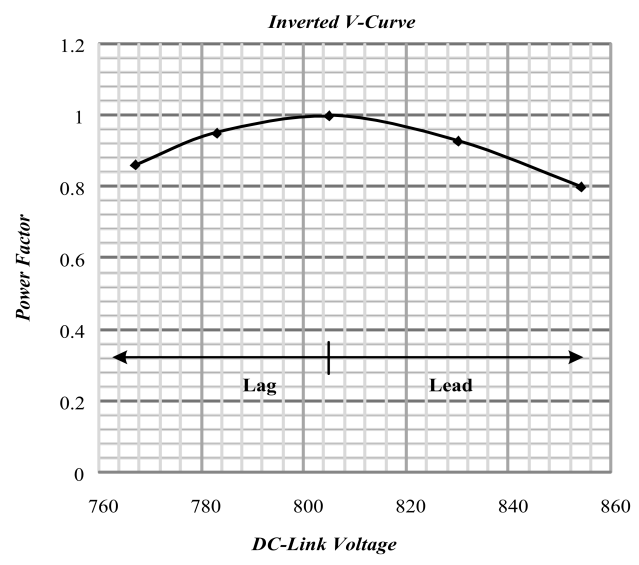

(b)

Figure 17. V-curve and inverted V-curve of the NSC. 


\section{Experimental Setup and Result}

The experimental setup of the NSC with induction motor connected to the source through the source inductance is shown in Figure 18. The experimental parameters are given in Table 4. The Hioki 3197 power quality analyzer is used to measure various system parameters. The source voltage is kept constant at $110 \mathrm{~V}$. Three LV20-P voltage sensors are used to measure source voltage to track instantaneous source angle $(\theta)$ for the rectifier operation of the NSC. The NSC input $\left(V_{a b}\right)$ and output $\left(V_{x y}\right)$ line voltages are shown in Figure 19.

Table 4. Parameter of Experimental Setup.

\begin{tabular}{cc}
\hline Item & Specification \\
\hline AC Source & $0-110 \mathrm{~V}$ \\
Source Inductance & $10 \mathrm{mH}$ \\
IGBT & KGT25N120NDH \\
Gate driver IC & MIC4425 \\
DSP & dsPIC33EP512MU810 \\
Software & MPLAB X IDE v2.10 \\
Sensors & LV-20P, LA-25P \\
Induction Motor & $1 \mathrm{hp}, 4$ Pole,110 V, 50 Hz
\end{tabular}

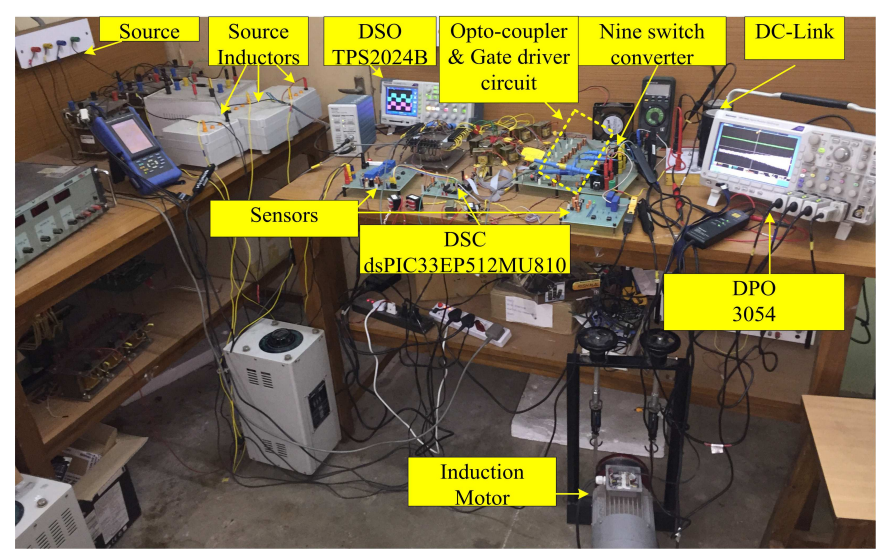

Figure 18. Experimental setup.

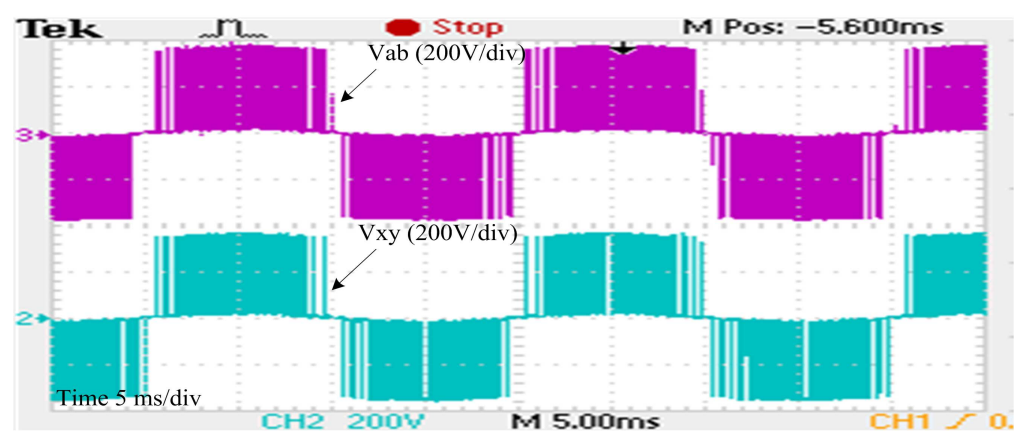

Figure 19. NSC input and output voltages: $V_{a b}, V_{x y}(200 \mathrm{~V} / \mathrm{div}, 5 \mathrm{~ms} / \mathrm{div})$.

To demonstrate reactive power transfer between source and NSC, $i_{q R E F}^{*}$ reference is varied. The operation of NSC is tested for different power factor conditions. 


\subsection{NSC Operated at Unity Power Factor Condition}

To operate NSC with induction motor drive at unity power factor, reference $i_{q R E F}^{*}$ is kept as $0 \mathrm{pu}$. The phase angle between $V_{s}$ and $i_{a}$ is $4.5^{\circ}$ as shown in Figure 20a. Ideally, as $i_{q R E F}^{*}$ is 0 , the angle between $V_{s}$ and $i_{a}$ must be equal to zero. However, due to the presence of harmonics in the system, a small reactive power is consumed by the harmonics present in pulsating nature of the input and output voltages. Figure 20b shows various parameters of the system. It is observed that a small reactive power of 16 VAR is absorbed by the NSC. The power factor is almost unity i.e., 0.974 PF. Figure 20c shows the phase voltage and phase current are in phase. The DC-link voltage is $380 \mathrm{~V}$. The NSC phase current is $0.64 \mathrm{~A}$.

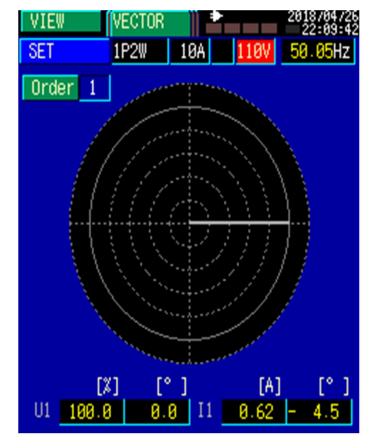

(a) Phase angle between $V_{s}$ and $i_{a}$

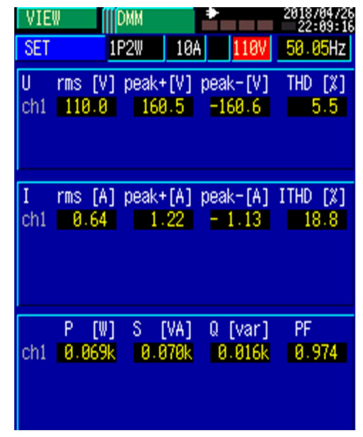

(b) System parameters

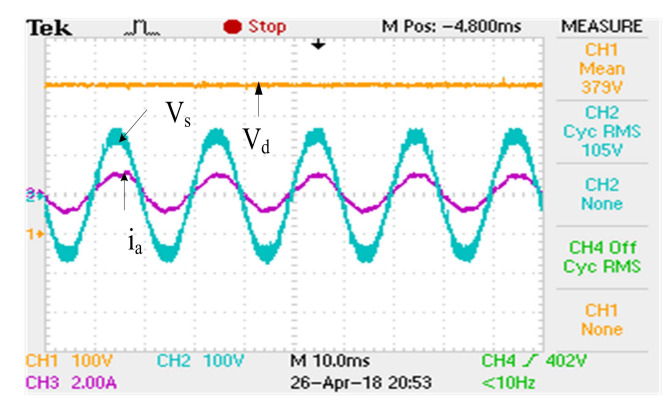

(c) Source voltage $\left(\mathrm{V}_{\mathrm{s}}\right)$ and NSC phase current $\left(\mathrm{i}_{\mathrm{a}}\right)$

Figure 20. Unity power factor operation of the NSC $i_{q R E F}^{*}=0 \mathrm{pu}: V_{d}, V_{s}, i_{a}(100 \mathrm{~V} / \mathrm{div}, 100 \mathrm{~V} / \mathrm{div}$, 2 A/div, $10 \mathrm{~ms} /$ div).

\subsection{NSC Operated at Lagging Power Factor Condition}

The lagging power factor operation of the NSC is tested for two conditions; $i_{q R E F}^{*}=0.7 \mathrm{pu}$, and $i_{q R E F}^{*}=0.3 \mathrm{pu}$. As shown in Figure 21a, when $i^{*}{ }_{q R E F}$ is $0.7 \mathrm{pu}, 81$ VAR reactive power is absorb by the NSC. The phase angle between $V_{s}$ and $i_{a}$ is $43.4^{\circ}$ (lag) i.e., 0.701 PF. The amplitude of phase current $i_{a}$ increased to $1.05 \mathrm{~A}$ as compared to the unity power factor operation. The DC-link voltage is droped to $369 \mathrm{~V}$. As shown in Figure 22b, when $i^{*}$ qREF is $0.3 \mathrm{pu}, 33$ VAR reactive power is absorb by the NSC. The phase angle between $V_{s}$ and $i_{a}$ is $22.2^{\circ}$ lag i.e., $0.896 \mathrm{PF}$. The amplitude of $i_{a}$ and DC-link voltage is $0.70 \mathrm{~A}$ and $371 \mathrm{~V}$ respectively. 


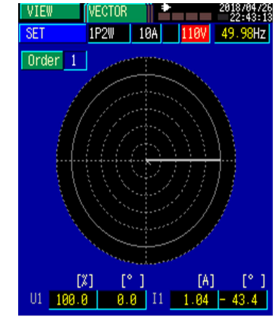

(a) Phase angle between $V_{s}$ and $i_{a}$ Tek n. estop +

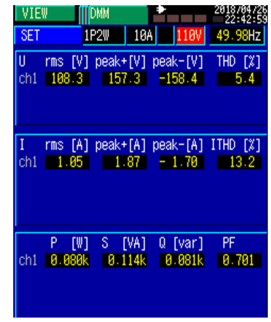

(b) System parameters M POS: $-4.800 \mathrm{~ms}$ MEASURE

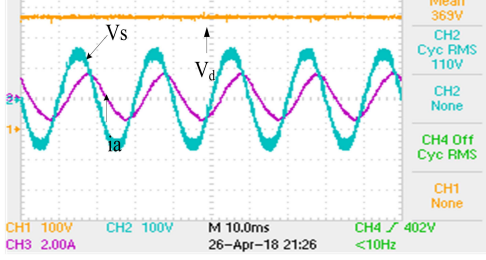

(c) Source voltage $\left(\mathrm{V}_{\mathrm{s}}\right)$ and NSC phase current $\left(\mathrm{i}_{\mathrm{a}}\right)$

(a) $i^{*}$ qREF $=0.7 \mathrm{pu}$
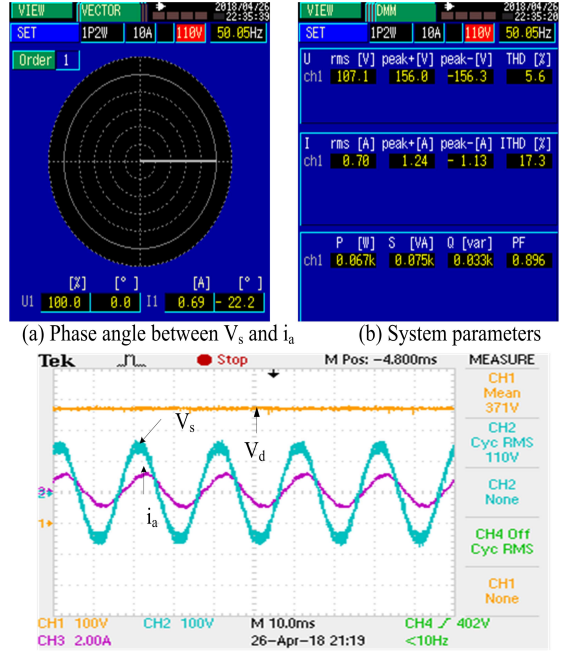

(c) Source voltage $\left(\mathrm{V}_{\mathrm{s}}\right)$ and NSC phase current $\left(\mathrm{i}_{\mathrm{a}}\right)$

(b) $i^{*}{ }_{q R E F}=0.3 \mathrm{pu}$

Figure 21. Lagging power factor operation of the NSC: $V_{d}, V_{s}, i_{a}(100 \mathrm{~V} / \mathrm{div}, 100 \mathrm{~V} / \mathrm{div}, 2 \mathrm{~A} / \mathrm{div}$, $10 \mathrm{~ms} / \mathrm{div})$.

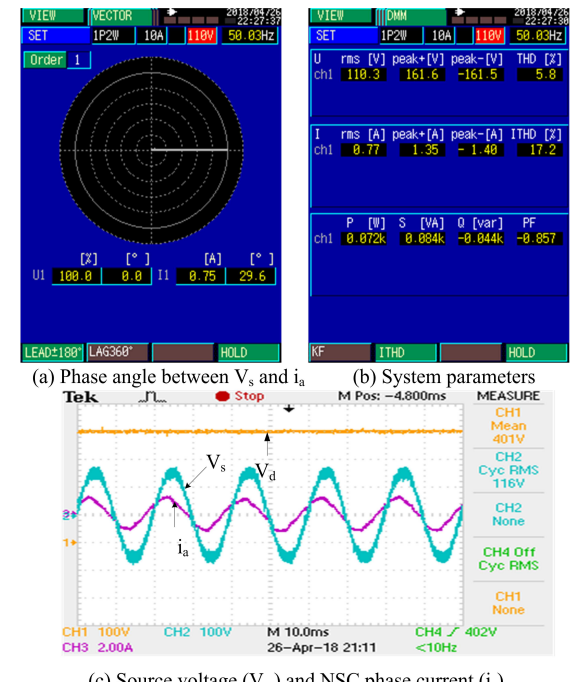

(c) Source voltage $\left(\mathrm{V}_{\mathrm{s}}\right)$ and NSC phase current $\left(\mathrm{i}_{\mathrm{a}}\right)$

(a) $i_{q R E F}^{*}=-0.4 \mathrm{pu}$
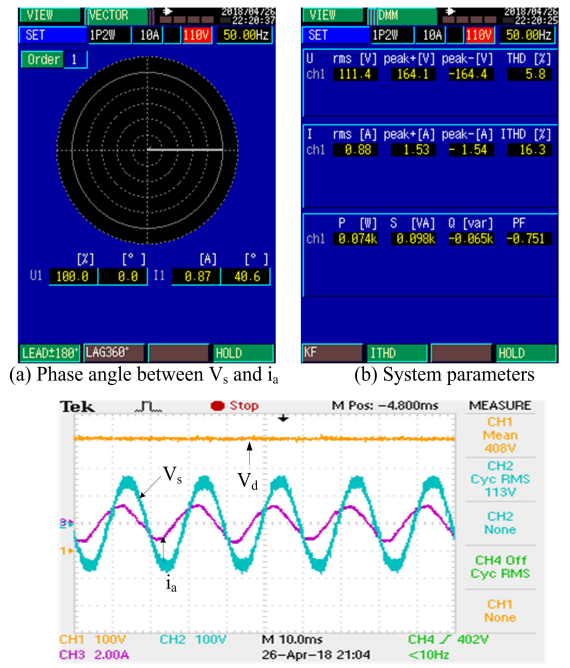

(c) Source voltage $\left(\mathrm{V}_{\mathrm{s}}\right)$ and NSC phase current $\left(\mathrm{i}_{\mathrm{a}}\right)$

(b) $i_{q R E F}^{*}=-0.6 \mathrm{pu}$

Figure 22. Leading power factor operation of the NSC: $V_{d}, V_{s}, i_{a}(100 \mathrm{~V} / \mathrm{div}, 100 \mathrm{~V} / \mathrm{div}, 2 \mathrm{~A} / \mathrm{div}$, $10 \mathrm{~ms} / \mathrm{div})$.

\subsection{NSC Operated at Leading Power Factor Condition}

The leading power factor operation of the NSC is also tested for two conditions; $i_{q R E F}^{*}=-0.4 \mathrm{pu}$, and $i_{\text {qREF }}^{*}=-0.6 \mathrm{pu}$. As shown in Figure 22a, when $i_{\text {qREF }}^{*}$ is $-0.4 \mathrm{pu}, 44$ VAR reactive power is delivered by the NSC. The phase angle between $V_{s}$ and $i_{a}$ is $29.6^{\circ}$ (lead) i.e., 0.857 PF. The amplitude of phase current $i_{a}$ increased to $0.88 \mathrm{~A}$ as compared to the unity power factor operation. The DC-link voltage is increases to $401 \mathrm{~V}$. As shown in Figure 22b, when $i_{q R E F}^{*}$ is $0.6 \mathrm{pu}, 65 \mathrm{VAR}$ reactive power is delivered by the NSC. The phase angle between $V_{s}$ and $i_{a}$ is $40.6^{\circ}$ (lead) i.e., 0.751 PF. The amplitude of $i_{a}$ and DC-link voltage is $0.88 \mathrm{~A}$ and $408 \mathrm{~V}$ respectively.

The positive reactive power shown in Figure 21 states that reactive is absorb by the NSC. The negative reactive power shown in Figure 22 states that the reactive power is delivered by NSC. 
Thus, the NSC with induction motor drive can be operated to absorb or to deliver reactive power to the connected source. Figure 23 show induction motor phase current on half load. The V-curve and inverter V-curve is plotted from experimental results is shown in Figure 24.

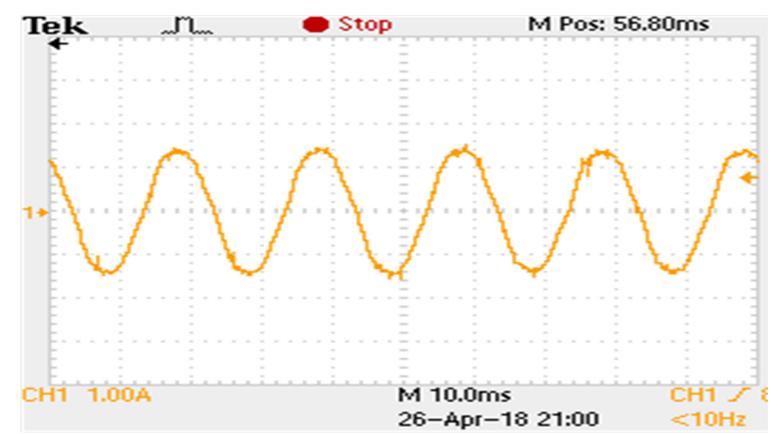

Figure 23. Induction motor current: $i_{L}(1 \mathrm{~A} / \mathrm{div}, 10 \mathrm{~ms} / \mathrm{div})$.

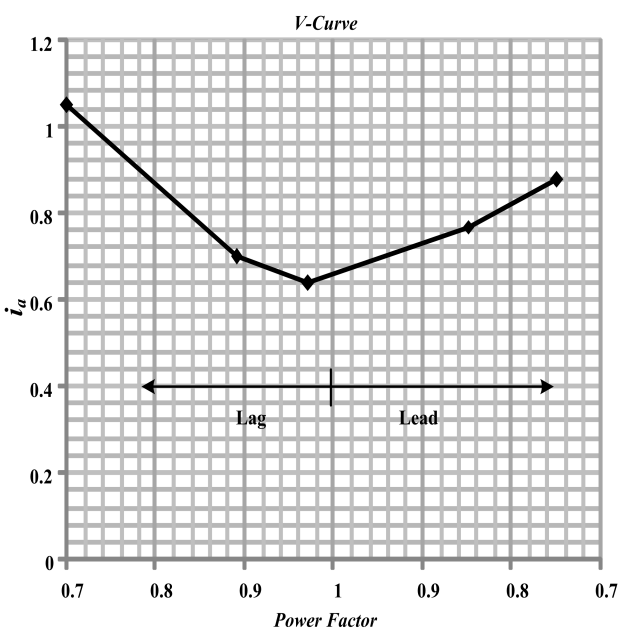

(a)

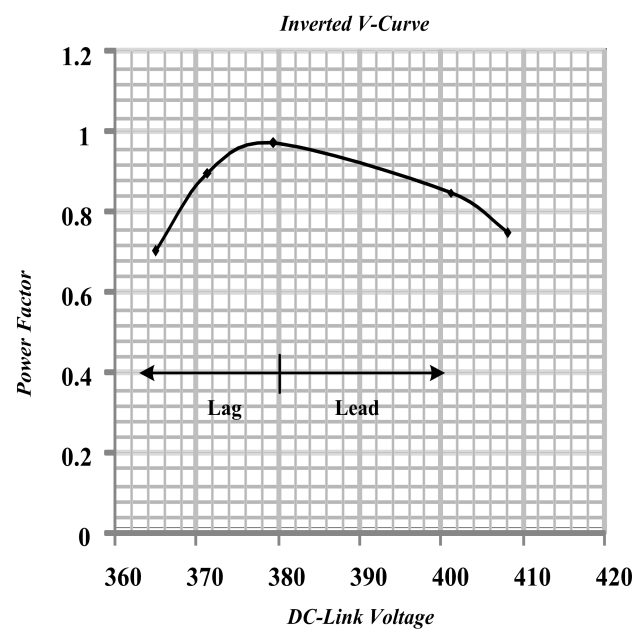

(b)

Figure 24. Experimental V-curve and inverted V-curve of the NSC.

Comparing V-curve of simulation and experimental showed in Figures 17a and 24a, it is observed that the amplitude of the NSC phase current $\left(i_{a}\right)$ is minimum near unity power factor. The amplitude of $i_{a}$ increased as the power factor lowered on both the lagging as well as leading side. Referring to Figure 6, the power factor at the PCC depends on the voltage magnitude of $V_{s}$ and $V_{\text {com }}$. The PCC voltage $V_{s}$ is constant and the magnitude of the $V_{\text {com }}$ is directly depends on DC-link voltage $\left(V_{d}\right)$ as per (2). Thus; controlling $V_{d}$, power factor at the PCC is controlled. Comparing inverted V-curve of simulation and experimental results showed in Figures $17 \mathrm{~b}$ and $24 \mathrm{~b}$, as the DC-link voltage increases power factor shifted from lagging to leading. Ideally, when the magnitude of the $V_{s}$ and $V_{c o m}$ is equal, the power factor at PCC must become zero. However, practically, there is a small voltage drop across the internal resistance of the source inductance. This drop varies with the amplitude of the current flowing through it. Thus; for different loading conditions, values of V-curve and inverter V-curve are different but nature of curve remain same. In experimental results switching and conduction losses are present whereas in simulation switches are ideal. Thus, there is a slight difference in the shape of V-curve and inverter V-curve of the NSC for simulation and experimental results. 


\section{Conclusions}

In this paper, the compact AC-DC-AC NSC is used as DSTATCOM and induction motor drive application. The switch count is reduced by $25 \%$ as compared to the conventional TSC. The control scheme is developed to operate NSC so as to mimic the operation of SG. The NSC can absorb or deliver reactive power at the PCC with induction motor drive. The NSC with induction motor drive is operated at desired power factor of the PCC. To verify simulation results, an experimental prototype is developed in the laboratory. The V-curve and inverted V-curve is obtained from simulation and experimental results are found similar in nature. Due to the presence of internal resistance of the source inductance and the switching losses in the experimental results, there is a slight difference in the shape of V-curve and inverted V-curve of the simulation and experimental results. The experimental results proved the practicability of the proposed control scheme to operate NSC as DSTATCOM and induction motor drive.

Author Contributions: C.J., M.C. and M.R. developed the concept: C.J. designed and performed the experiments: C.J. and M.C. wrote the paper; M.R. analyzed the data. These authors contributed equally to this work.

Funding: This research received no external funding.

Acknowledgments: Authors acknowledges the VNIT, Nagpur for providing infrastructure support.

Conflicts of Interest: The authors declare no conflict of interest.

\section{Abbreviations}

The following abbreviations and symbols are used in this manuscript:

$\begin{array}{ll}\text { DG } & \text { Distribution generation } \\ \text { NSC } & \text { Nine switch converter } \\ \text { DSTATCOM } & \text { Distribution static compensator } \\ \text { TSC } & \text { Twelve switch converter } \\ \text { SG } & \text { Synchronous generator } \\ \text { PCC } & \text { Point of common coupling } \\ \text { FACTS } & \text { Flexible Alternating Current Transmission System } \\ \mathrm{V}_{\mathrm{s}} & \text { Phase voltage of grid } \\ \mathrm{i}_{\mathrm{S}} & \text { Phase current of grid } \\ \mathrm{i}_{1} & \text { Phase current of reactive load connected across NSC } \\ \mathrm{i}_{\mathrm{a}} & \text { Phase current of NSC } \\ \mathrm{V}_{\mathrm{com}} & \text { NSC input phase voltage } \\ \mathrm{V}_{\mathrm{inv}} & \text { NSC output phase voltage } \\ \mathrm{i}_{\mathrm{L}} & \text { NSC output phase current } \\ \phi_{\mathrm{a}} & \text { Angle between } \mathrm{V}_{\mathrm{S}} \text { and } \mathrm{i}_{\mathrm{a}} \\ \phi_{1} & \text { Angle between } \mathrm{V}_{\mathrm{s}} \text { and } \mathrm{i}_{1} \\ \phi_{0} & \text { Angle between } \mathrm{V}_{\text {inv }} \text { and } \mathrm{i}_{\mathrm{L}} \\ \mathrm{V}_{\mathrm{d}} & \text { DC-link voltage } \\ \theta & \text { Instantaneous angle of the grid } \\ \delta & \text { Power angle between } \mathrm{V}_{\mathrm{s}} \text { and } \mathrm{V}_{\text {com }} \\ \mathrm{Ref}_{\text {rec }} & \text { Modulation references for rectifier operation } \\ \mathrm{Ref}_{\text {inv }} & \text { Modulation reference for inverter operation } \\ \mathrm{V}_{\mathrm{c}} & \text { Carrier reference } \\ \mathrm{m}_{\mathrm{r}} & \text { Modulation index of Ref } \\ \mathrm{L}_{\mathrm{s}} & \text { Source inductance } \\ \mathrm{R}_{\mathrm{s}} & \text { Internal resistance of the source inductor } \\ \mathrm{a}, \mathrm{b}, \mathrm{c} & \text { Input terminals of the NSC } \\ \mathrm{x}, \mathrm{y}, \mathrm{z} & \text { Output terminals of NSC } \\ \mathrm{N} & \text { Pommon point of negative dc-link voltage } \\ \mathrm{V}_{\mathrm{aN}} & \\ \mathrm{V}_{\mathrm{xN}} & \end{array}$


$\mathrm{Id}^{*} \quad$ Generated active current reference

Qrec Reactive power at PCC

$\mathrm{Q}_{\mathrm{NSC}} \quad$ Reactive power of NSC

Q load Reactive power of other load connected across NSC

$\mathrm{Q}_{\text {ref }} \quad$ Desired reactive power at PCC

$\mathrm{V}_{\mathrm{ab} 1} \quad$ Fundamental component of the NSC input line voltage

$\mathrm{V}_{\mathrm{xy} 1} \quad$ Fundamental component of NSC output line voltage

\section{References}

1. Ding, T.; Kou, Y.; Yang, Y.; Zhang, Y.; Yan, H.; Blaabjerg, F. Evaluating maximum photovoltaic integration in district distribution systems considering optimal inverter dispatch and cloud shading conditions. IET Renew. Power Gener. 2017, 11, 165-172. [CrossRef]

2. Blaabjerg, F.; Ma, K. Wind Energy Systems. Proc. IEEE 2017, 105, 2116-2131.

3. Bose, B.K. Power Electronics, Smart Grid, and Renewable Energy Systems. Proc. IEEE 2017, 105, $2011-2018$. [CrossRef]

4. Popavath, L.N.; Kaliannan, P. Photovoltaic-STATCOM with Low Voltage Ride through Strategy and Power Quality Enhancement in a Grid Integrated Wind-PV System. Electronics 2018, 7, 51. [CrossRef]

5. Blaabjerg, F.; Yang, Y.; Yang, D.; Wang, X. Distributed Power-Generation Systems and Protection. Proc. IEEE 2017, 105, 1311-1331. [CrossRef]

6. Arya, S.R.; Singh, B.; Niwas, R.; Chandra, A.; Al-Haddad, K. Power Quality Enhancement Using DSTATCOM in Distributed Power Generation System. IEEE Trans. Ind. Appl. 2016, 52, 5203-5212. [CrossRef]

7. Sekhar, V.C.; Kant, K.; Singh, B. DSTATCOM supported induction generator for improving power quality. IET Renew. Power Gener. 2016, 10, 495-503. [CrossRef]

8. Liu, C.; Wu, B.; Zargari, N.R.; Xu, D.; Wang, J. A Novel Three-Phase Three-Leg AC/AC Converter Using Nine IGBTs. IEEE Trans. Power Electron. 2009, 24, 1151-1160. [CrossRef]

9. Liu, X.; Wang, P.; Loh, P.C.; Blaabjerg, F. A Compact Three-Phase Single-Input/Dual-Output Matrix Converter. IEEE Trans. Ind. Electron. 2012, 59, 6-16. [CrossRef]

10. Liu, X.; Loh, P.C.; Wang, P.; Blaabjerg, F. A Direct Power Conversion Topology for Grid Integration of Hybrid AC/DC Energy Resources. IEEE Trans. Ind. Electron. 2013, 60, 5696-5707. [CrossRef]

11. Diab, M.S.; Elserougi, A.A.; Abdel-Khalik, A.S.; Massoud, A.M.; Ahmed, S. A Nine-Switch-Converter-Based Integrated Motor Drive and Battery Charger System for EVs Using Symmetrical Six-Phase Machines. IEEE Trans. Ind. Electron. 2016, 63, 5326-5335. [CrossRef]

12. Dehghan, S.M.; Mohamadian, M.; Yazdian, A. Hybrid Electric Vehicle Based on Bidirectional Z-Source Nine-Switch Inverter. IEEE Trans. Veh. Technol. 2010, 59, 2641-2653. [CrossRef]

13. Liu, C.; Wu, B.; Zargari, N.; Xu, D. A novel nine-switch PWM rectifier-inverter topology for three-phase UPS applications. In Proceedings of the 2007 European Conference on Power Electronics and Applications, Aalborg, Denmark, 2-5 September 2007; pp. 1-10. [CrossRef]

14. Loh, P.C.; Zhang, L.; Gao, F. Compact Integrated Energy Systems for Distributed Generation. IEEE Trans. Ind. Electron. 2013, 60, 1492-1502. [CrossRef]

15. Qin, Z.; Loh, P.C.; Blaabjerg, F. Application Criteria for Nine-Switch Power Conversion Systems with Improved Thermal Performance. IEEE Trans. Power Electron. 2015, 30, 4608-4620. [CrossRef]

16. Ali, K.; Das, P.; Panda, S.K. A Special Application Criterion of Nine-Switch Converter with Reduced Conduction Loss. IEEE Trans. Ind. Electron. 2017, 64, 2853-2862. [CrossRef]

17. Rahman, K.; Al-Emadi, N.; Iqbal, A.; Rahman, S. Common mode voltage reduction technique in a three-to-three phase indirect matrix converter. IET Electr. Power Appl. 2018, 12, 254-263. [CrossRef]

18. Park, K.; Lee, K.B.; Blaabjerg, F. Improving Output Performance of a Z-Source Sparse Matrix Converter Under Unbalanced Input-Voltage Conditions. IEEE Trans. Power Electron. 2012, 27, 2043-2054. [CrossRef]

19. Shi, T.; Zhang, X.; An, S.; Yan, Y.; Xia, C. Harmonic suppression modulation strategy for ultra-sparse matrix converter. IET Power Electron. 2016, 9, 589-599. [CrossRef]

20. Ledezma, E.; McGrath, B.; Munoz, A.; Lipo, T.A. Dual AC-drive system with a reduced switch count. IEEE Trans. Ind. Appl. 2001, 37, 1325-1333. [CrossRef] 
21. Blaabjerg, F.; Freysson, S.; Hansen, H.H.; Hansen, S. A new optimized space-vector modulation strategy for a component-minimized voltage source inverter. IEEE Trans. Power Electron. 1997, 12, 704-714. [CrossRef]

22. da Silva, C.H.; Pereira, R.R.; da Silva, L.E.B.; Lambert-Torres, G.; Bose, B.K.; Ahn, S.U. A Digital PLL Scheme for Three-Phase System Using Modified Synchronous Reference Frame. IEEE Trans. Ind. Electron. 2010, 57, 3814-3821. [CrossRef]

(C) 2018 by the authors. Licensee MDPI, Basel, Switzerland. This article is an open access article distributed under the terms and conditions of the Creative Commons Attribution (CC BY) license (http:/ / creativecommons.org/licenses/by/4.0/). 